\title{
Comparison of high-performance ion chromatography technique with microbiological assay of myo-inositol in plant components of poultry feeds*
}

\author{
R. Duliński, A. Starzyńska-Janiszewska, B. Stodolak and K. Żyła ${ }^{1}$
}

\author{
University of Agriculture in Krakow, Faculty of Food Technology, \\ Department of Food Biotechnology \\ Balicka 122, 30-149 Kraków, Poland
}

(Received 20 December 2010; revised version 8 March 2011; accepted 12 March 2011)

\begin{abstract}
An ion chromatography technique (HPAEC-PAD) was employed for determination of inositol in plant components of feeds as an alternative to a microbiological assay. The study included analysis of total, free and dialysable inositol released from samples by an in vitro procedure simulating digestion in the gastrointestinal tract of birds. Inositol was separated on the high-performance anionexchange CarboPack MA1 column and monitored by the pulsed amperometric detection (PAD). As compared to the HPAEC-PAD technique, microbiological assay produced 2-3 fold lower values of total inositol, probably due to myo-inositol stereoselectivity of Saccharomyces cerevisiae ATCC 9080 analytical strain. The overall correlation coefficient was $0.989,0.941$ and 0.736 for total, free and dialysable inositol, respectively. Microbiological method of analysis rather than the HPAECPAD technique may be recommended for determination of dialysable myo-inositol released from feed samples during in vitro digestions that simulate gastrointestinal tract of birds. The HPAEC-PAD technique was more sensitive, convenient and suitable for total inositol determination.
\end{abstract}

KEY WORDS: poultry, soyabean meal, inositol, dialysable inositol, microbiological assay, ion chromatography

\footnotetext{
* Supported by the Ministry of Science and Higher Education, Grant No. N N311 307736

${ }^{1}$ Corresponding author: e-mail: k.zyla@ur.krakow.pl
} 


\section{INTRODUCTION}

Plant cells metabolize myo-inositol via a number of pathways, leading to glucuronate, pectin and ascorbic acid synthesis, to the formation of sucrose and its galactinol conjugates, synthesis of phytate and myo-inositol phosphates that are important in signal transduction mechanisms as well as to generation of phospholipids that constitute biological membranes (Loewus and Murthy, 2000; Mueller-Roeber and Pical, 2002; Eyster, 2006; Van Meer et al., 2008). Myoinositol is considered to be a growth factor for certain organisms and an indicator of abnormal metabolism or disease in humans (Holub, 1986). In rodents and fish its deficiency may be associated with fatty liver, intestinal lipodystrophy and a lack of growth. Deranieh et al. (2009) reported that the lack of myo-inositol in the cultivation medium inhibited proliferation and caused death of human cells in vitro.

Phytates - salts of phytic acid (myo-inositol hexakisphosphate) are the major storage form of phosphorus in cereal grains, legumes and oilseeds. In the nutrition of monogastric animals and humans these compounds are antinutrients due to the ability to chelate metal ions and to form complexes with protein and carbohydrates reducing their bioavailability (Greiner et al., 2006). Enzymatic hydrolysis of phytates by endo- or exogenous phytases leads to formation of myo-inositol phosphate intermediates in addition to inorganic phosphate (Viveros et al., 2000; Selle and Ravindran, 2007). D-chiro-inositol and its methylated form, pinitol, the major cyclitols of soyabean are also suspected to play a role in diseases prevention and health-promoting (Lee et al., 2003).

Żyła and co-workers (2004) found significantly increased body weight gains of broilers fed low phosphorus diets supplemented with $0.1 \%$ of myo-inositol. A similar level of myo-inositol might be liberated by a synergistic action of phytase A and a fungal acid phosphatase (phytase B) on phytate molecule when poultry feeds are supplemented with both enzymes (Żyła et al., 2004). It seems possible therefore that enzymatically generated myo-inositol (EGI) resulting from action of phytases on feed phytates, may modulate metabolism and improve performance of growing broilers. Determination of different forms of myo-inositol in feeds and feedstuffs is necessary to estimate the EGI pool among different myo-inositol phosphates generated during enzymatic hydrolysis of phytates both in vitro and in vivo.

A couple of analytical methods have already been published for determination of myo-inositol in foods. These include microbiological assay (Norris and Darbre, 1956), enzymatic test (Kozuma et al., 2001), gas chromatography method (Perello et al., 2004) and HPLC procedure (Indyk and Woollard, 1994). Generally, the procedures need chemical derivatization of samples, base on indirect measurements, 
are time-consuming and not completely reliable for routine analyses. Since its introduction, pulsed amperometric detection (PAD) has considerably improved the sensitivity and selectivity of separation of carbohydrates and alditiols by highperformance anion-exchange chromatography (HPAEC) (Corradini et al., 1997; Tagliaferri et al., 2000). The literature data about using the HPAEC-PAD procedure for determination of myo-inositol in feeds and feedstuffs are scarce, however.

From analytical standpoint, myo-inositol present in feeds or foods may be assayed either as a "free" inositol that is usually extracted by $0.04 \mathrm{M} \mathrm{HCl}$ or as "total" inositol determined after hydrolysis of a sample under harsh acidic conditions (1-6 M HCl, 120-140 ${ }^{\circ} \mathrm{C}$ ). From nutritional standpoint, however, it would be of interest to determine the amounts of inositol that are liberated from feeds during digestion of a sample in the intestinal tract. This might be achieved by using an in vitro procedure that simulates digestion in the intestinal tract of broilers and by determination of "dialysable" inositol content in feed components.

The objective of the current study was to determine the total, free and dialysable inositol contents in feed components and in fully formulated maize-soyabean meal-based and wheat-soyabean meal-based feed samples by the HPAEC-PAD technique (Technical Note, 2000) as well as by a conventional microbiological assay with Saccharomyces cerevisiae ATTC 9080 strain and to evaluate the methods in terms of different inositol isomers quantification.

\section{MATERIAL AND METHODS}

\section{Material}

Samples of wheat, conventional or genetically modified (GM) maize (BT maize MON-810), conventional or GM soyabean meal (RoundUpReady) and samples of fully-formulated wheat-soyabean meal-based and maize-soyabean meal-based feeds were obtained from National Research Institute of Animal Production (Balice, Poland). myo-Inositol, myo-inositol-2-monophosphate and sodium hydroxide (50\%) for HPAEC were obtained from Fluka (Poland). Inositol assay medium, malt and yeast extracts, peptone, dextrose, agar were from Becton, Dickinson \& Company (USA). The strain of Saccharomyces cerevisiae ATCC 9080 was purchased from American Type Culture Collection. All other chemicals were of analytical grade.

\section{Enzymes}

Pepsin (declared activity of 225000 units $\cdot \mathrm{mg}^{-1}$ ) and pancreatin (activity 
$8 \times$ U.S. Pharmakopeia) were purchased from Sigma Chemical Co (St. Louis, USA).

\section{Total inositol determination}

Proper amounts of feed or feedstuff (100-200 mg) were subjected to acid hydrolysis with $2 \mathrm{ml}$ of $1 \mathrm{M} \mathrm{HCl}$ in Duran ${ }^{\circledR}$ glass tubes $(16 \times 160 \mathrm{~mm})$ for $48 \mathrm{~h}$ at $123^{\circ} \mathrm{C}$. After cooling the samples were prepared further according to method of Norris and Darbre (1956). Sample pH was adjusted to 4.8-5.0 and inositol content was assayed in the hydrolyzate.

\section{Free inositol determination}

Samples $(1.00 \mathrm{~g})$ of feeds or diet ingredients were homogenized and extracted with $0.04 \mathrm{M} \mathrm{HCl}$ according to method of Norris and Darbre (1956). Sample $\mathrm{pH}$ was adjusted to $4.8-5.0$ and then subjected to microbiological and HPLC assays.

\section{In vitro digestions and dialysable inositol}

The in vitro procedure of Żyła et al. (1995) that simulates digestion in the intestinal tract of broilers was used. Briefly, the procedure comprised three consecutive incubations of samples at $40^{\circ} \mathrm{C}$ and at $\mathrm{pH} 5.80$ for $30 \mathrm{~min}$, at $\mathrm{pH}$ 2.75 for $45 \mathrm{~min}$, and at $\mathrm{pH} 6.10$ for $240 \mathrm{~min}$, that simulated digestion in the crop, gizzard and duodenum, respectively. The acidic digest contained pepsin (3000 units per gram of a sample) whereas duodenal digestion was carried out with pancreatin in dialysis bags immersed in buffered $0.1 \mathrm{M} \mathrm{NaCl}$ solution. In samples of dialysates $\mathrm{pH}$ was adjusted to 4.8-5.0 and inositol concentration was assessed by both methods.

\section{Microbiological assay of myo-inositol}

Maintenance of organism. The strain of S. cerevisiae ATCC 9080 was maintained by monthly subculturing for $24 \mathrm{~h}$ at $30^{\circ} \mathrm{C}$ on malt-agar slants. The medium used consists of yeast extract $(0.3 \%)$, malt extract $(0.3 \%)$, peptone $(0.5 \%)$, dextrose $(1 \%)$ and agar $(2 \%)$.

Basal medium. Inositol assay medium was an inositol-free dehydrated medium containing all other nutrients and vitamins essential for the cultivation of $S$. cerevisiae ATCC 9080 (Difco ${ }^{\text {TM }}$ Inositol Assay Medium). The addition of inositol in specified increasing concentration gave a growth response of a test organism that was measured turbidimetrically (Norris and Darbre, 1956). 
Procedure. A loopful of culture from stock culture slant of $S$. cerevisiae ATCC 9080 was removed and suspended in $10 \mathrm{ml}$ of sterile $\mathrm{NaCl}$ solution $(0.85 \%)$. Cells were centrifuged $(2000 \mathrm{~g}, 10 \mathrm{~min})$ and supernatants were decanted. Cells were washed three times with sterile $0.85 \% \mathrm{NaCl}$ solution. One $\mathrm{ml}$ of cell suspension was diluted in $1000 \mathrm{ml}$ of $0.85 \% \mathrm{NaCl}$ and $40 \mu 1$ portions of the suspension were used to inoculate each assay flask. The standard curve was obtained by using myo-inositol at concentrations from 0 to $2 \mu \mathrm{g} \cdot \mathrm{ml}^{-1}$. Following inoculation, flasks were incubated at $30^{\circ} \mathrm{C}$ for $20-24 \mathrm{~h}$. To stop growth of yeast flasks were placed in the refrigerator for $30 \mathrm{~min}$. Growth was measured turbidimetrically at $660 \mathrm{~nm}$. The concentration of myo-inositol in samples was calculated using only those values that did not vary more than $\pm 10 \%$ from the average.

\section{Chromatographic system and detection}

All chromatograms were generated using a HPLC system that consisted of a isocratic pump model ISO-3000 (Dionex, Sunnyvale, CA), a pulsed amperometric detector (Dionex Model ED50), a Rheodyne rotary injection valve with $20 \mu 1$ injection loop and a column CarboPac MA1 $8.5 \mu \mathrm{m}$ particle dia. $(250 \times 4 \mathrm{~mm}$ i.d.) coupled with a guard CarboPac MAl column (5 x $4 \mathrm{~mm}$ i.d.). The flow-through detection cell contained a gold working electrode and a $\mathrm{Ag} / \mathrm{AgCl}$ reference electrode. Acquisition and processing of chromatographic data were done by a Chromeleon PC Integration software ver. 8.0 (Dionex). All chromatographic analysis were carried out at ambient temperature with flow-rates of $0.4 \mathrm{ml} \cdot \mathrm{min}^{-1}$ using $1 \mathrm{M}$ sodium hydroxide as eluent. The sample before injection was filtered through $0.22 \mu \mathrm{m}$ nylon syringe filters. Conditions employed here were suitable for the efficient separation and detection of sugars and alditiols (Dionex, Application Note 66). The detection mode is called integrated pulsed amperometric detection (IPAD).

\section{Recovery experiment}

Recovery of inositol standard was determined by careful, 3-step mixing of myoinositol with GM soyabean meal to have final concentration of added inositol at $2 \mathrm{mg} \cdot \mathrm{g}^{-1}$ of meal (dry substance basis) and assaying total, free and dialysable inositol concentrations by both analytical procedures.

\section{Statistical analysis}

Data were collected in triplicate and subjected to two-way analysis of variance. 
In case of significant interaction between analytical method and analysed material one-way analysis of variance was employed for each method separately and differences among means were assessed using post-hoc Tuckey test of the Statistica for Windows v. 9,0 statistical package. Correlation and regression analysis was performed using appropriate modules of the same software. Statistical significance was accepted at $\mathrm{P}<0.05$.

\section{RESULTS}

A linear relationship between detector response and myo-inositol concentration over $0-100 \mu \mathrm{g} \cdot \mathrm{l}^{-1}$ was observed in the high performance anion exchange chromatography with pulsed amperometric detection (HPAEC-PAD) technique. Correlation coefficient of 0.998 between myo-inositol concentration and signal strength of the detector was calculated with $100 \mathrm{ng}$ being the lowest myoinositol concentration in standard solutions. Based on a signal vs noise ratio, detection limit of $10 \mathrm{ng}$ was determined for the HPAEC-PAD procedure (in the microbiological assay the limit of detection was $2 \mu \mathrm{g}$ ). The relative standard deviation of the retention time for selected standards was $0.15 \%$ for one-day analysis (data not shown). Typical chromatogram of myo-inositol standard $(25 \mu \mathrm{g})$ is depicted on Figure 1 along with a chromatogram of "total" inositol extracted from a sample of maize-soyabean meal diet. On Figure 2, the chromatogram of $25 \mu \mathrm{g}$ myo-inositol is contrasted with the elution pattern of 25 $\mu \mathrm{g}$ of $m y o$-inositol mixed with $50 \mu \mathrm{g}$ of myo-inositol 2-monophosphate. The latter

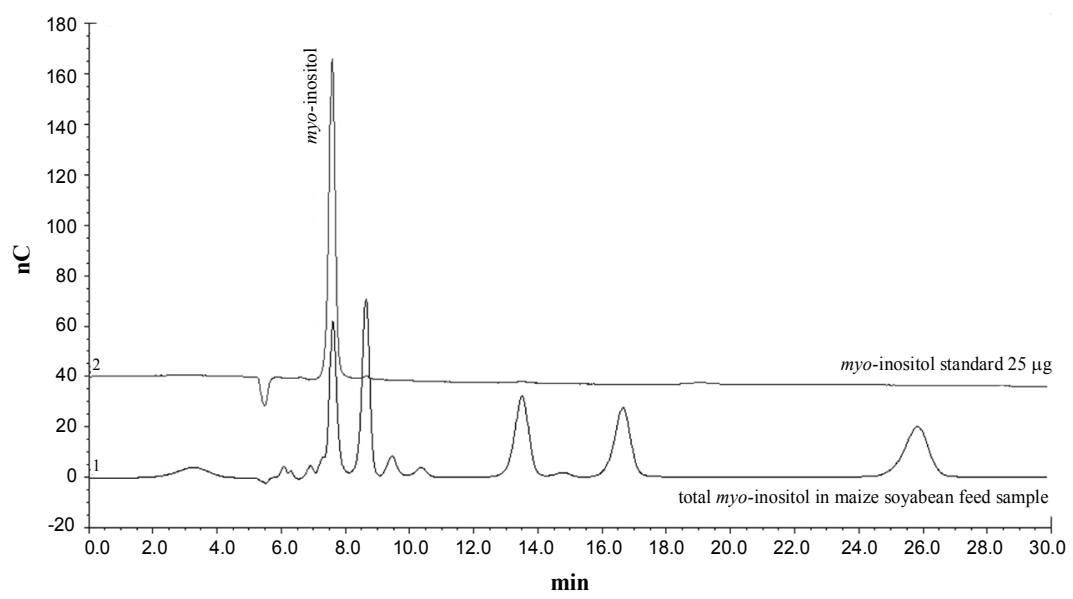

Figure 1. Overlayed HPAEC-PAD chromatograms of myo-inositol standard and total inositol extracted from a sample of maize-soyabean meal diet. Chromatographic conditions: column CarboPack MA-1; mobile phase $1 \mathrm{M}$ sodium hydroxide. Flow rate, $0.4 \mathrm{ml} \cdot \mathrm{min}^{-1}$ at room temperature, pulse amperometric mode as described in Material and methods 
substance had much longer retention time and was hardly noticed by the PAD detector.

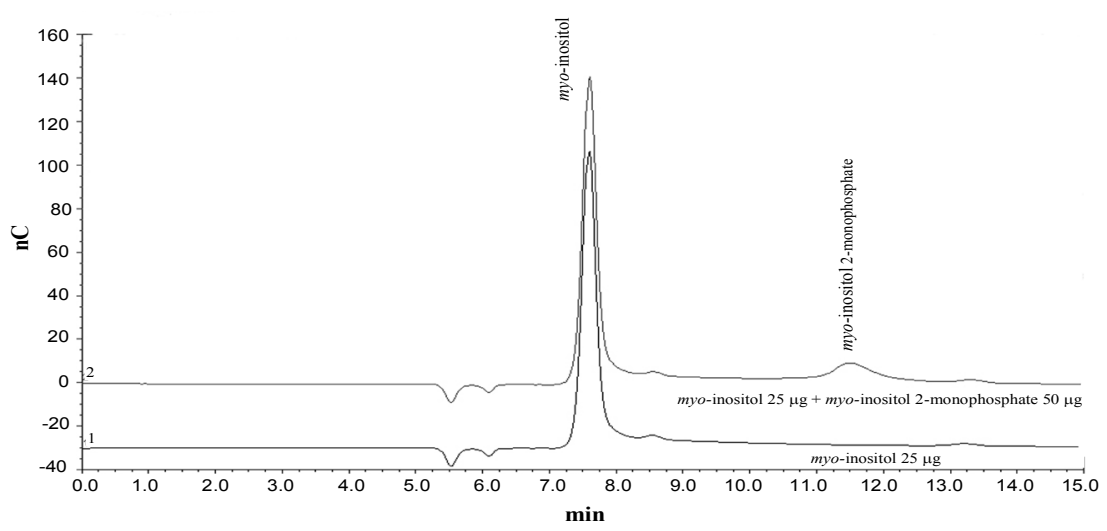

Figure 2. Overlayed chromatograms of myo-inositol and myo-inositol 2-monophosphate standards. Chromatographic conditions: column CarboPack MA-1; mobile phase $1 \mathrm{M}$ sodium hydroxide. Flow rate, $0.4 \mathrm{ml} \cdot \mathrm{min}^{-1}$ at room temperature, pulse amperometric mode as described in Material and methods

There was a significant influence of the analysed material and of the method of analysis and a significant interaction of these factors on total, free and dialysable inositol determined in feeds and feedstuffs (two-way analysis of variance). To overcome the interactions, means were calculated separately for the microbiological and HPLC methods using one-way analysis of variance (Table 1). The highest values of total inositol were determined by the HPAECPAD method in GM and in conventional soyabean meal samples (7957 and $5971 \mu \mathrm{g} \cdot \mathrm{g}^{-1}$, respectively). Total inositol determined in these samples by the microbiological assay amounted 2392 and $2636 \mu \mathrm{g} \cdot \mathrm{g}^{-1}$, respectively. Both analytical methods showed that conventional and GM maize samples had the lowest content of total inositol among all samples studied. Wheat-soyabean mealbased feed was found to have higher total inositol concentration than maizesoyabean meal-based feed when assayed by the HPAEC-PAD procedure but not in the microbiological assay. Both methods produced similar amounts of total inositol in GM and conventional cultivars of maize but analyses by both methods revealed a significantly higher total inositol content in GM than in conventional soyabean meal. The values of total inositol determined by the microbiological assay were systematically lower than the amounts determined by the HPLC technique and accounted for 33\% in GM soyabean to $49 \%$ in wheat of the content obtained with chromatographic method. 


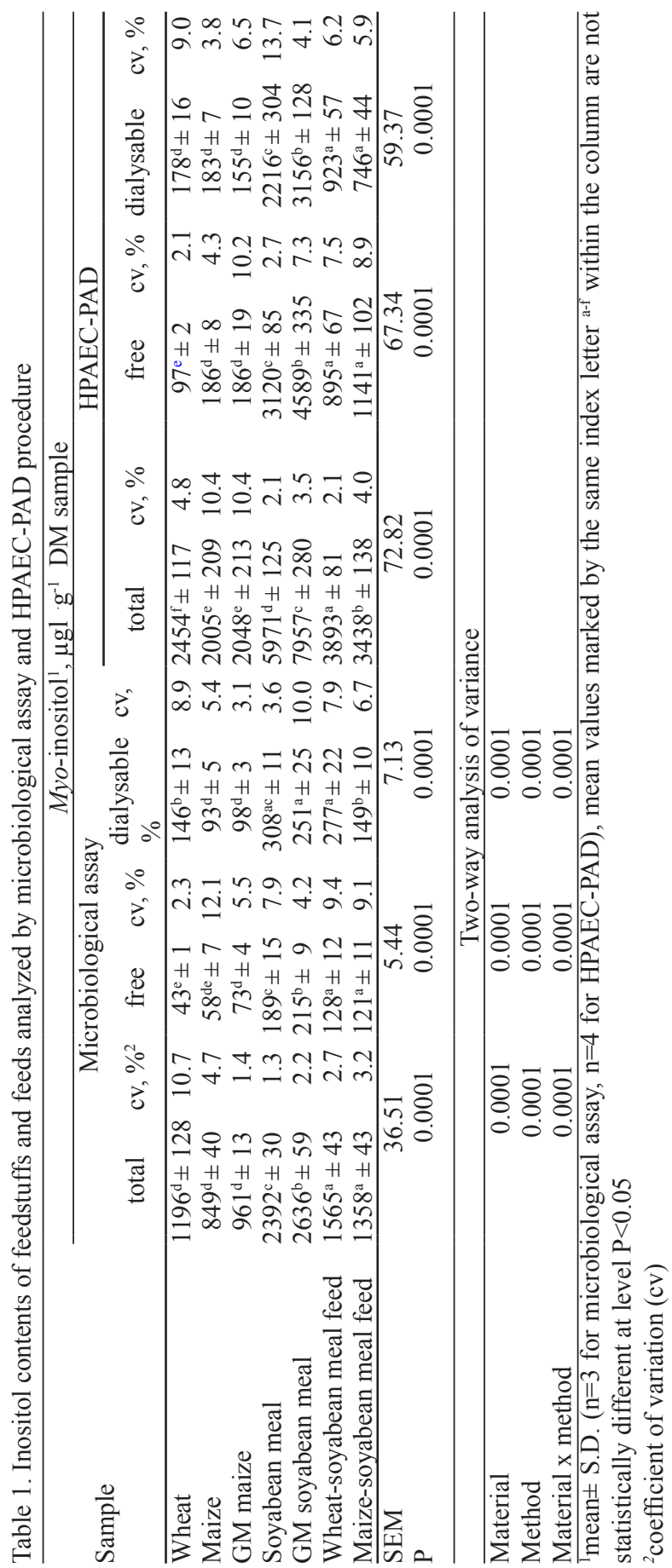


Recovery experiment performed with a sample of GM soyabean meal revealed that 97,91 and $85 \%$ of added standard was determined in total, free and dialysable inositol, respectively, whereas using the microbial assay 88,98 and $99 \%$, of total, free and dialysable inositol, respectively, was recovered.

The concentrations of free inositol when expressed as a percentage of total inositol content varied from $3.6 \%$ in wheat to $8.9 \%$ in maize-soyabean meal-based feed when assayed by the microbiological procedure whereas the HPAEC-PAD method produced a variation ranging from $3.95 \%$ for wheat to $58 \%$ for GM soyabean meal. Generally, in samples containing soyabean meal, be it conventional or GM, the ratio of free to total inositol was much higher when determined by the chromatographic procedure. The concentrations of dialysable inositol determined by the microbiological method were significantly higher than those found for free inositol and accounted for 10.9 to $17.7 \%$ of total inositol. Furthermore, the difference between these two forms was higher in samples containing wheat than in samples comprising maize. Surprisingly, these observations were not confirmed by the HPAEC-PAD procedure where dialysable inositol concentrations determined in majority of samples were significantly lower than corresponding free inositol levels. In contrast to microbiological assay, the chromatographic determination of free an dialysable inositol resulted in enormous variation of their contents ranging from 97 to $4589 \mu \mathrm{g} \cdot \mathrm{g}^{-1}$ (free inositol) and 178 to $3156 \mu \mathrm{g} \cdot \mathrm{g}^{-1}$ (dialysable inositol) for wheat and GM soyabean meal, respectively. Comparable amounts of free inositol were assessed by both methods in fully-formulated wheat-based diet and maize-based diet, but microbiological assay gave significantly higher dialysable inositol in wheat-based feed. There were no differences in free inositol or in dialysable inositol between samples of conventional and GM maize.

Regression analysis of the data generated by the two analytical procedures revealed a highly significant relationship $(\mathrm{P}<0.05)$ for the combined data of total, free and dialysable inositol with the correlation coefficient of 0.843 (data not shown). The relationship between these two data sets was much stronger when samples of conventional and GM soyabean meal were excluded from the analysis $(r=0.962$; Figure 3$)$. For the particular forms of inositol that were analysed in this work correlation coefficients of $0.98,0.94$, and 0.74 for the total, free and dialysable inositol, respectively, were calculated whereas after excluding soyabean samples the values found were $0.92,0.93$, and 0.82 , respectively. 
Microbiological assay $=-51.33+42655 \times$ HPAEC-PAD

Correlation coefficient: $r=0.96222$

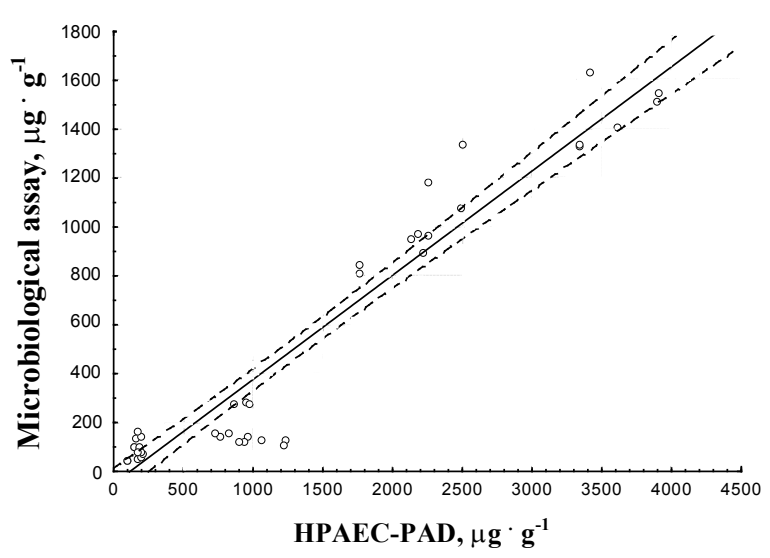

Figure 3. Correlation between inositol concentrations determined by microbiological assay and HPAEC-PAD technique after excluding samples of soyabean

\section{DISCUSSION}

Microbiological and liquid chromatography methods of total inositol determination have already been compared during analysis of dietetic milk powders (Tagliaferrii et al., 2000). Similarly to our findings, the authors reported systematically higher concentrations of total inositol determined by the HPAECPAD technique (420 to $1340 \mu \mathrm{g} \cdot \mathrm{g}^{-1}$ ) than by the microbiological procedure ( 270 to $\left.1120 \mu \mathrm{g} \cdot \mathrm{g}^{-1}\right)$. Our findings clearly indicate, however, that this discrepancy cannot be attributed to different extraction methods or to inability of $S$. cerevisiae ATCC 9080 strain to assimilate inositol monophosphate, as was thought before. In the study presented here, the same acidic extract was applied, after neutralization, to both analytical methods. Furthermore, even in the mild extraction conditions applied for free inositol determination, the difference between values given by the two methods was striking. To the contrary, Indyk and Woollard (1994) reported similar amounts of free inositol in skimmed milk powders, wholemilk powders and milk infant formulas, determined by a HPLC and a microbial procedure with Saccharomyces uvarum. In our HPAEC-PAD method, myoinositol monophosphate did not co-elute with myo-inositol as shown on Figure 2. Considering the very similar stereochemistry of myo- and chiro-inositol, both isomers may be expected to have the same retention time. It seems therefore that the only idea that can be offered for the explanation of differences in total inositol as well as in free inositol given by the two methods tested here is coelution of inositol isomers other than myo-inositol from the Carbopack MA1 
column, on the one hand, and myo-inositol stereo-selectivity of the analytical Saccharomyces strain used in microbiological procedure, on the other. Kong et al. (2008), with the help of capillary electrophoresis coupled with electrochemical detection, successfully separated chiro- from myo-inositol in samples of black rice bran and reported that the D-chiro-inositol may contribute 30 to $44 \%$ of both isoforms in different varieties of rice. Soyabean seeds are known to contain up to $0.9 \%$ of pinitol, a methylated form of D-chiro-inositol that can be separated from D-chiro- and myo-inositol by gas chromatography (Lee et al., 2003; Gomes et al., 2005). In our study, high proportion of free to total inositol in samples of soyabean meal determined by the chromatographic procedure was not confirmed in the microbiological assay. This finding suggests again stereo-selectivity of the Saccharomyces cerevisiae ATTC 9080 strain. Pinitol and D-chiro-inositol, the predominant cyclitols of soyabean seed coat, most probably co-elueted from the analytical column with myo-inositol while microbiological assay determined myo-inositol only.

Soyabean meal is known to be high in protein and soyabean meal samples that underwent in vitro digestions simulating the intestinal tract of birds were high in sugars in addition to amino acids (Żyła et al., 1995). Surprisingly, with a few exceptions (wheat, wheat-soyabean diet), the concentrations of dialysable inositol determined by the chromatographic method were lower than the amounts of free inositol. The microbiological assay, on the other hand, produced values of dialysable inositol, at least a few percentage points higher than free inositol. The differences between dialysable and free inositol where the highest in wheat and wheat-based diet samples that are known for high endogenous phytate-degrading enzymes activities whose action may release myo-inositol from phytate during digestion (Żyła et al., 2004). Eggleston (1999) reported that hydrophobic amino acids act as foulants of the gold electrode used in pulsed amperometric detection and lead to overestimation or to suppressive quantification of different sugars and cyclitols, including inositol. The author recommended changing of column and reducing ionic strength of eluent as possible solutions. Unfortunately, in our work, none of these remedies produced significant improvements. Regressions analysis of data obtained in our study clearly indicate that soyabean meal samples, and particularly those that underwent in vitro digestions, significantly lowered correlation between the two methods tested. It should be emphasized therefore that the HPAEC-PAD chromatographic procedure cannot be recommended for quantification of enzymaticaly generated inositol, i.e. myo-inositol released from diet components by the action of phytate-degrading enzymes. Norris and Dabre (1953), using a strain of Schizosaccharomyces pombe for microbiological determination of inositol in plant tissues reported total inositol concentration in soyabean meal at $5980 \mu \mathrm{g} \cdot \mathrm{g}^{-1}$. Interestingly, we found quite similar level of this 
compound $\left(5971 \mu \mathrm{g} \cdot \mathrm{g}^{-1}\right)$ using the HPAEC-PAD method, but more than 2-fold lower concentration $\left(2392 \mu \mathrm{g} \cdot \mathrm{g}^{-1}\right)$ was determined by microbiological assay. It may be speculated again, that in contrast to Saccharomyces cerevisiae ATCC 9080, Schizosaccharomyces pombe, originally employed as a testing strain in inositol assays was not stereoselective.

Amounts of total inositol determined by Koning (1994) in wheat-based products by gas chromatography method ranged from 2400 to $9500 \mu \mathrm{g} \cdot \mathrm{g}^{-1}$ for wheat flour and wheat bran, respectively, whereas free inositol was found to amount 80 to $290 \mu \mathrm{g} \cdot \mathrm{g}^{-1}$, respectively. The values found for wheat flour are comparable to data generated in our studies by the HPAEC-PAD method that comprised all cyclitols rather than myo-inositol exclusively. The amounts of inositol that may be determined in wheat-based products range from $40 \mu \mathrm{g} \cdot \mathrm{g}^{-1}$ (free inositol in this study, microbiological assay) to $11500 \mu \mathrm{g} \cdot \mathrm{g}^{-1}$ in stone-ground wheat bread (total inositol; Clements and Darnell, 1980). In our study, dialysable inositol content in wheat was $146 \mu \mathrm{g} \cdot \mathrm{g}^{-1}$ when assayed by microbiological method and $178 \mu \mathrm{g} \cdot \mathrm{g}^{-1}$ with the HPAEC-PAD procedure. This indicates inositol bioavailability from wheat to be 7 to $12 \%$. Comparable values characterized conventional and GM maize. There seems to be a possibility of substantial increase in bioavailability of inositol from feed components when exogenous phytate-degrading enzymes of microbial origin are added to diets. Diet components with high phytate content may be rich sources of enzymatically generated myo-inositol whereas soyabean meal seems to be a good supply of highly available cyclitols other than myoinositol.

\section{CONCLUSIONS}

In conclusion it may be postulated that myo-inositol released from plant diet constituents that are high in phytate can be followed by microbiological assay rather than by ion chromatography technique coupled with electrochemical detection. In determination of inositol liberated from soyabean-containing samples particularly those that were subjected to multiple in vitro digestions electrochemical detection may not be employed and microbiological assay with Saccharomyces cerevisiae ATCC 9080 will not account for changes in the concentrations of chiro-inositol or pinitol. The chromatographic method, on the other hand, was much more sensitive and seems to be more convenient and suitable for routine total inositol determination. 


\section{REFERENCES}

Clements Jr., R.S., Darnell B., 1980. Myo-inositol content of common foods: development of a high myo- inositol diet. Amer. J. Clin. Nutr. 33, 1954-1967

Corradini C., Canali G., Cogliandro E., Nicoletti I., 1997. Separation of alditiols of interests in food products by high-performance anion-exchange chromatography with pulsed amperometric detection. J. Chromatogr. A 791, 343-349

Deranieh R.M., Greenberg M.L., 2009. Cellular consequences of inositol depletion. Biochem. Soc. Trans. 37, 1099-1103

Eggleston G., 1999. Improved quantitative ion chromatography of industrial sugars: removal of interfering amino acids. Food Chem. 65, 483-491

Eyster K.M., 2006. The membrane and lipids as integral participants in signal transduction: lipid signal transduction for the non-lipid biochemist. Adv. Physiol. Educ. 31, 5-16

Gomes C. I., Obendorf R. L., Horbowicz M., 2005. Myo-inositol, D-chiro-inositol, and D-pinitol synthesis, transport, and galactoside formation in soybean explants. Crop Sci. 45, 1312-1319

Greiner R., Konietzny U., Jany K.-D., 2006. Phytate - an undesirable components of plant-based foods? Z. Ernährungsmed. 8, 18-28

Holub B.J., 1986. Metabolism and function of myo-inositol and inositol phospholipids. Annu. Rev. Nutr. 6, 563-97

Indyk H.E., Woollard D.C., 1994. Determination of free myo-inositol in milk and infant formula by high-performance liquid chromatography. Analyst 119, 397-402

Koning A.J., 1994. Determination of myo-inositol and phytic acid by gas chromatography using scyllitol as a internal standard. Analyst 119, 1319-1323

Kong L., Wang Y., Cao Y., 2008. Determination of Myo-inositol and D-chiro-inositol in black rice bran by capillary electrophoresis with electrochemical detection. J. Food Compos. Anal. 21, 501-504

Kozuma T., Takahasi M., Endoh T., Kaneko R., Ura N., Shimamoto K., Watanabe N., 2001. An enzymatic cycling metod for measurment of myo-inositol in biological samples. Clin. Chim. Acta 312, 143-151

Lee Y.K., Park P.B., Park Y.-I., Chung N., 2003. Comparison of soybean varieties for cyclitol content in soybean curd wastewaters. Agr. Chem. Biotechnol. 46, 148-151

Loewus F.A., Murthy P. P.N., 2000. myo-Inositol metabolism in plants. Plant Sci. 150, 1-19

Mueller-Roeber B., Pical C., 2002. Inositol phospholipid metabolism in Arabidopsis. Characterized and putative isoforms of inositol phospholipid kinase and phosphoinositide-specific phospholipase C1. Plant Physiol. 130, 22-46

Norris F.W., Darbre A., 1956. The microbiological assay of inositol with a strain of Schizosaccharomyces pombe. Analyst 81, 394-400

Perello J., Isern B., Costa-Bauza A., Grases F., 2004, Determination of myo-inositol in biological samples by liquid chromatography-mass spectrometry. J. Chromatogr. B 802, 367-370

Selle P.H., Ravindran V., 2007. Microbial phytase in poultry nutrition. Anim. Feed Sci. Tech. 135, $1-41$

Tagliaferri E.G., Bonetti G., Blake C.J., 2000. Ion chromatographic determination of inositol in infant formulae and clinical products for enteral feeding. J. Chromatogr. 879, 129-135

Technical Note No. 66, 2000. Analysis of Carbohydrates by High Performance Anion Exchange Chromatography with Pulsed Amperometric Detection (HPAEC-PAD), Dionex Corporation

Van Meer G., Voelker D.R., Feigenson G.W., 2008. Membrane lipids: where they are and how they behave. Nat. Rev. Mol. Cell Biol. 9, 112-124 
Viveros A., Centeno C., Brenes A., Canales R., Lozano A., 2000. Phytase and acid phosphatase activities in plant feedstuffs. J. Agr. Food Chem. 48, 4009-4013

Waagbo R., Sandnes K., Lie O., 1998. Effects of inositol supplementation on growth, chemical composition and blood chemistry in Atlantic salmon, Salmo salar L., fry. Aquacult. Nutr. 4, 53-59

Żyła K., Ledoux D.R., Garcia A., Veum T.L., 1995. An in vitro procedure for studying enzymic dephosphorylation of phytate in maize-soya bean feeds for turkey poults. Brit. J. Nutr. 74, 3-17

Żyła K., Mika M., Stodolak B., Wikiera A., Korelski J., Świątkiewicz S., 2004. Towards complete dephosphorylation and total conversion of phytates in poultry feeds. Poultry Sci. 83, 1175-1186 